\section{Pakistan must invest in adaptation}

Floods in Pakistan this year alone have killed hundreds of people, left millions homeless and destroyed crops over tens of thousands of hectares. In its Global Climate Risk Index 2014, the think tank Germanwatch ranked Pakistan third in its list of countries most affected by climate change, after Haiti and the Philippines.

Yet Pakistan's climatechange budget for 2013-14 was $44 \%$ lower than the previous year's. Furthermore, the federal government has largely devolved responsibility for environmental issues to the provinces, which cannot or will not commit resources to climate-change policies.

It is important that the principles of disaster management are simplified so that the public can understand them and question government responses where necessary. Many citizens already realize that towns are being flooded as a result of illegal building on neighbouring floodplains and waterways.

Diplomacy in India and Pakistan has secured reciprocal arrangements for flood relief, but this is not enough. Rainfall data need to be coordinated and exchanged between the two countries to improve flood forecasting and disastermanagement governance through organizations such as the South Asian Association for Regional Cooperation.

Pakistan and most other developing countries have little influence on actions determined by Western countries to reduce carbon emissions. The best option for developing nations is to offset the negative effects of rising temperatures and extreme events by developing weather-tolerant crops and housing, by planning for effective land use, and by improving energy efficiency.
Information Technology, Islamabad, Pakistan. arehmancheema@gmail.com

\section{Keep files small to curb energy use}

Electronic publishing circumvents environmental issues caused by paper use and the shipment of heavy journals. But more thrift is needed to reduce the energy consumed by Internet servers, which already accounts for $2 \%$ of global energy production (see, for instance, go.nature.com/dmqn9a).

Large video and PDF files are downloaded and distributed by e-mail, often thousands of times. Minimizing the size of such files would reduce server energy usage and allow easier access by people in developing countries and rural areas that have slow Internet connections.

Server energy is also wasted in distributing figures at unnecessarily high resolution. Governments and public organizations are particularly guilty (see, for example, an 11-megabyte PDF from the European Research Council: go.nature.com/lwcuyx).

More scientific journals should ask authors to submit their manuscripts with lowresolution illustrations, which can then be upgraded for publication. Publishers of open-access journals might even consider offering a discount on publication charges for manuscript files that are smaller than, say, one megabyte.

David Gurwitz Tel-Aviv University, Israel. gurwitz@post.tau.ac.il

\section{Tourism is least of cetaceans' problems}

Ecotourism boats could indeed be harming dolphins and whales, for example by interrupting their foraging behaviour (see Nature 512, 358; 2014). But many whale-watchers do right by the animals and follow good practice. The major threats to cetaceans are still hunting, fishing, military sonar, undersea explosives and pollution.

According to the International Whaling Commission, there were just 32 collisions with ecotourism boats, resulting in 4 whale fatalities, between 1885 and 2010 (see go.nature.com/ vehx93). Private boaters who do not follow proper guidelines are a problem. And ecotourism boats frighten Icelandic minke whales (Balaenoptera acutorostrata) probably because the animals confuse them with Iceland's commercial whale-hunting vessels.

Even where ecotourism boats have damaged cetacean populations - as in New Zealand's Doubtful Sound, where tours caused bottlenose-dolphin numbers to fall by 11 between 1997 and 2005 - these declines pale in comparison to the hundreds of pilot whales that are butchered each year in the Faroe Islands, or to the similar numbers of dolphins slaughtered in Taiji, Japan. Moreover, some 300,000 cetaceans die every year as a result of entanglement in fishing gear (see go.nature.com/bh2wl7).

Dale Frink Rancho Santa Margarita, California, USA. dalefrink@gmail.com

\section{Sanctions derail wildlife protection}

Blanket economic sanctions on politically unstable regimes that are rich in biodiversity deny local people access to international funding for wildlife conservation and management (see A. Waldron et al. Proc. Natl Acad. Sci. USA 110, 1214412148; 2013). More-targeted restrictions could secure major biodiversity gains for relatively minor investment.

The Red Sea coral-reef ecosystems of Sudan, for example, are among the world's healthiest, with robust populations of top predators; in South Sudan, one of the largest migrations of terrestrial mammals occurs each year. The international community should recognize the importance of such unique ecological attributes and help to safeguard them through adequate funding and research.

Terrorism, war and humanrights atrocities in Sudan's Darfur province are rightly condemned, but the remaining $75 \%$ of the country is relatively peaceful. Indeed, wildlife protection brings socio-economic benefits that help to alleviate poverty and resolve conflict (see W. M. Adams et al. Science 306, 1146-1149; 2004). Conservation should not be derailed by sanctions.

Nigel Hussey University of Windsor, Ontario, Canada. nehussey@uwindsor.ca

\section{Great crested grebe usurps badger}

Michael Brooke's charming centennial reappraisal of Julian Huxley's Courtship Habits of the Great Crested Grebe (Nature 513, 484; 2014) missed an opportunity to mention the starring role these birds had in Evelyn Waugh's 1938 satirical novel Scoop.

In this novel, Priscilla Boot - sister of nature writer William Boot - mischievously meddles with one of William's newspaper columns, swapping "badger" throughout for "great crested grebe". The essay is duly printed - with the bird as its protagonist.

A prodigious correspondence ensues: one letter asks whether the author condones the practice of baiting these rare and beautiful birds with terriers; another challenges him to produce a single authenticated case of a great crested grebe attacking young rabbits. Roger C. Prince Stonybrook Apiary, Annandale, New Jersey, USA. rogercprince@gmail.com 